\title{
Gender Issues in Mathematics: An Ontario Perspective
}

\author{
Jennifer Hall \\ University of Ottawa
}

\begin{abstract}
In many developed countries, including Canada, it is often perceived that gender issues in mathematics have been "solved" and are no longer a relevant and timely issue. In this article, I challenge this perception by providing an overview of gender issues in mathematics in three domains-achievement, attitude, and participation-from the elementary school level to the university level. My analysis of several sources of data from Ontario is compared to a meta-analysis of research involving data from culturally similar countries to Canada, for example, Australia, United Kingdom. The data primarily arise from large-scale mathematics assessments, for example, PISA and EQAO, and national statistics databases, for example, Statistics Canada and National Center for Education Statistics. Counter to the aforementioned perception, this analysis indicates that gender issues still exist in mathematics in developed countries, including Canada. The gender gap is particularly wide in terms of students' attitudes and participation: Males have substantially more positive attitudes toward mathematics and higher levels of participation in non-mandatory levels of mathematics than do females. The article concludes with a discussion of the implications of the findings and suggestions of possible steps that may be taken to help ameliorate the current situation.
\end{abstract}

Gender issues have long been a heated topic of debate in mathematics education. Early research (e.g., Fruchter, 1954; Stafford, 1972) tended to focus on biological explanations for perceived differences between males and females in spatial perception and mathematical reasoning ability. However, other researchers questioned the biological focus and examined other issues that might affect students' experiences with mathematics. In the late 1970s, a seminal study of U.S. high school students by Fennema and Sherman (1977) marked a turning point in the focus of mathematics education research about gender issues. Fennema and Sherman found that when two factors, the number of prior mathematics courses taken and experience with spatial activities, were controlled, no statistically significant gender differences in spatial abilities existed. The researchers also investigated students' attitudes toward mathematics, and found that males generally had more positive attitudes than females toward the subject area. Based on their findings, Fennema and Sherman posited that students' attitudes were socially constructed as opposed to biologically determined. Since this study, research regarding gender issues in mathematics education has generally moved away from biologically deterministic arguments. 
In the 1990s, in particular, there was a great deal of research that focused on gender issues in mathematics, investigating how social factors, including parents' views and the manner in which mathematics is taught, may impact female and male students' attitudes, achievements, and participation in mathematics in different ways (e.g., Boaler, 1997; Gavin, 1996; Morrow \& Morrow, 1995). However, in recent years, the amount of research on this topic has significantly decreased (Damarin, 2008), arguably in part due to the perception that the problem has been "solved."

Although significant progress has been made with regard to gender issues in mathematics over the past few decades, much work still needs to be done to achieve gender equity, and further research into the topic is warranted. This article investigates three key facets of gender issues in mathematics: achievement, attitude, and participation. These topics were selected due to their highly inter-related nature: Attitudes toward mathematics and achievement in mathematics are reciprocal constructs, and these in turn can influence participation in mathematics (Boaler, 1997; McGraw, Lubienski, \& Strutchens, 2006; Picker \& Berry, 2000, 2001). As noted earlier, the perception of gender issues being 'solved' is common in developed countries. Thus, in each section of this article, I begin by examining each topic (achievement, attitude, or participation) from a broad international perspective, by discussing research from developed countries that are culturally similar to Canada, for example, United States and Australia. The data discussed primarily arise from large-scale assessments of mathematics and their accompanying student questionnaires (elementary and secondary level) and national statistical databases (university level). To provide local context, I examine the topic with respect to the Canadian province of Ontario. Ontario was selected as it is Canada's most populous province by a significant margin, containing nearly $40 \%$ of the nation's population (Statistics Canada, 2010a), thus making it a good representation of the country as a whole. Furthermore, Ontario elementary and secondary school students participate in mandatory annual large-scale assessments of mathematics (with associated student questionnaires), which provide comparable data to those analyzed by authors from culturally-similar countries to Canada. I summarize each section by highlighting similarities and differences among the geographic locales discussed, in order to probe into whether gender issues in mathematics are similar among the culturally-similar countries, even though their educational systems differ. The article concludes with a discussion of the findings presented and their implications.

\section{Achievement}

My focus in this section is on comparing males' and females' achievement in mathematics, as measured by large-scale assessments at both the elementary and secondary level. I first discuss male and female students' achievement in mathematics in the United States, Australia, New Zealand, and the United Kingdom, countries that are culturally-similar to Canada. Then, to provide local context, I investigate the achievement of Ontario students on the Grade 3, 6, and 9 large-scale provincial assessments of mathematics. I conclude by summarizing and drawing comparisons among the findings from these four countries and the 
province of Ontario to investigate whether gendered similarities in student achievement exist among the countries examined.

\section{International Perspectives}

In the United States, one of the most well-known large-scale assessments with a mathematics portion is the National Assessment of Educational Progress (NAEP), which is conducted with students in Grade 4, 8, and 12 every four years. Since 1990, the NAEP large-scale assessment has been aligned with the Standards $(1989 ; 1991 ; 1995 ; 2000)$ of the National Council of Teachers of Mathematics (McGraw et al., 2006), and as such, focuses on important mathematical concepts. McGraw et al. reviewed NAEP data from 1990 to 2003, and they found that gender gaps in mathematics achievement in favour of males, although small, were persistent across the years for which they examined data. Also, the achievement gap in mathematics, in males' favour, widened with an increase in grade level (from Grade 4 to Grade 12) and was more pronounced at the highest levels of achievement. Therefore, not only are gender gaps in achievement on the NAEP in males' favour enduring over time, they also are largest at higher grade levels, when mathematics achievement is essential for many students' post-secondary plans.

A second U.S. example relates to Scholastic Assessment Test (SAT) data. The SAT is a standardized test that is required for admission into many American universities, and is comprised of critical reading, writing, and mathematics portions. Karp and Shakeshaft (1997) analyzed data from American students from 1982 to 1995 on the mathematics portion of the SAT, which is scored on a scale from 200 to 800 . The researchers found that females scored on average 45.5 points lower than males. Similar to the NAEP data, the gender gap was largest in the top achievement levels of the SAT (scores between 750 and 800). In fact, the male-to-female ratio in this top level was consistently 4:1 from 1992 to 1995. Thus, far more males are high achievers on the mathematics portion of the SAT, which increases their probability of acceptance to mathematics-related university programs over females.

Data from Australia and New Zealand were investigated in a meta-analysis of large-scale national and international assessments of mathematics (from the elementary to secondary level) by Vale (2008). From 2000 to 2004, most assessments showed no significant differences in achievement between boys and girls, although boys typically achieved higher mean scores. However, in 2006, on the Programme for International Student Achievement (PISA) large-scale assessment of the mathematics skills of 15-year-olds, there was a statistically significant achievement gap in favour of boys in both Australia and New Zealand. Similar to the findings of McGraw et al. (2006) regarding the NAEP data, Vale found that, for most assessments examined in Australia and New Zealand, there were more boys than girls at the highest achievement level.

Students in the United Kingdom and the United States also participated in the 2006 PISA large-scale assessment of mathematics skills of 15-year-olds. Although the two counties ranked very differently overall in mathematics scores (mean scores of 474 for the United Kingdom compared to 495 for the United States), the gendered results, in favour of males, were similar between the two countries (OECD, 2007). The gender gap was more pronounced in the United 
Kingdom, with a mean score for boys that was a statistically significant 17 points higher than the mean score for girls, as compared to a nine point achievement gap in the United States (OECD). Notably, in all four countries discussed (Australia, New Zealand, United Kingdom, and United States), the 2006 PISA assessment of 15-year-olds showed statistically significant gender gaps in mathematics achievement in males' favour.

\section{Ontario Perspective}

Since the 2003/2004 school year, students in Grade 3 (ages 8-9), Grade 6 (ages 11-12), and Grade 9 (ages 14-15) in Ontario have been required to participate in annual provincial large-scale mathematics assessments, which are created and conducted by the Education Quality and Accountability Office (EQAO). The assessments include both closed (multiple-choice) and open (short and long answer) questions, which are intended to assess students' understanding of the Ontario mathematics curriculum. Students' papers are scored with a level that corresponds to their success in the large-scale mathematics assessment. The levels used by EQAO are "aligned with the four-level scale developed by the Ministry of Education and used on the Provincial Report Card" (EQAO, 2008). Level 3 is the "provincial standard," which means students are meeting grade level expectations with a "considerable level of achievement" (Ontario Ministry of Education, 2005a, p. 20). In the following discussion, I explore gender differences in the percentage of students meeting or exceeding Level 3 in Grades 3, 6, and 9 (Academic and Applied), from 2003/2004 to 2007/2008. For the sake of brevity, the term "attained" will be used to refer to "met or exceeded," that is, Level 3 or 4, with regard to the provincial standard.

At the Grade 3 level, boys and girls have performed nearly identically each year. In 2003/2004, 2006/2007, and 2007/2008, a slightly higher percentage of girls than boys attained the provincial standard (by $2 \%, 1 \%$, and $2 \%$ respectively). In $2004 / 2005,66 \%$ of both boys and girls attained the provincial standard. In 2005/2006, $1 \%$ more boys than girls attained the provincial standard. Thus, there is no significant difference in Grade 3 girls' and boys' achievement on the EQAO mathematics assessment over the five years examined.

At the Grade 6 level, the results were nearly identical to those of Grade 3 students: Boys and girls performed virtually identically each year, although there were no years in which a higher percentage of boys attained the provincial standard than girls. In 2004/2005, similar to the Grade 3 results, an equal percentage of boys and girls attained the provincial standard (60\% in this case). In the other four years, a higher percentage of girls attained the provincial standard (by $4 \%$ in $2003 / 2004,3 \%$ in $2005 / 2006$, and $2 \%$ in both $2006 / 2007$ and 2007/2008). Although a higher percentage of girls than boys tended to attain the provincial standard on the Grade 6 EQAO assessment of mathematics, girls' advantage was minimal ( $2 \%$ to $4 \%$ ).

In Grade 9, there are two different assessments of mathematics, one for each level of the course: Academic or Applied. The Ontario Ministry of Education (2005b) defines Academic courses as those that 'develop students' knowledge and skills through the study of theory and abstract problems. These courses focus on the essential concepts of a subject and explore related concepts as well. They incorporate practical applications as appropriate" (p. 6). Applied courses "focus 
on the essential concepts of a subject, and develop students' knowledge and skills through practical applications and concrete examples. Familiar situations are used to illustrate ideas, and students are given more opportunities to experience hands-on applications" (p. 6). The Academic stream in Grade 9 and 10 courses typically leads to University-Preparation courses at the Grade 11 and 12 level, whereas the Applied stream typically leads to College- or ApprenticeshipPreparation courses.

In Grade 9 Academic mathematics, a higher percentage of boys than girls attained the provincial standard on the EQAO assessment every year except $2003 / 2004$, when $68 \%$ of both boys and girls attained the provincial standard. In both $2004 / 2005$ and $2005 / 2006,2 \%$ more boys than girls attained the provincial standard, whereas in 2006/2007 and 2007/2008, boys' advantage was 3\%. Overall, boys in Grade 9 Academic mathematics tend to perform better than girls on the EQAO mathematics assessment, although their advantage over girls is minimal ( $2 \%$ to $3 \%)$.

In Grade 9 Applied mathematics, the situation is very similar to that of Grade 9 Academic mathematics: Each year, a higher percentage of boys attained the provincial standard. Notably, the gap between girls' and boys' achievement on the Grade 9 Applied EQAO mathematics assessment has been widening over time, from a $1 \%$ gender gap in favour of boys in 2003/2004 to a 5\% gender gap in 2007/2008 (Gender gaps in the interim years were 3\%, 4\%, and $4 \%$ respectively). Similar to Grade 9 Academic mathematics students, boys in Grade 9 Applied mathematics classes tend to outperform girls on the EQAO assessment, although their advantage is small (1\% to $5 \%)$.

\section{Summary: Achievement Data}

A great deal of data on student achievement in mathematics on large-scale assessments has been presented for the United States, Australia, New Zealand, and the United Kingdom, and the Canadian province of Ontario. Consequently, to summarize key points of these findings, Table 1 provides a synopsis of the data discussed in the section.

As can be seen in Table 1, the United States' NAEP and SAT assessments showed achievement gaps in favour of boys. Similarly, the 2006 PISA assessment showed statistically significant achievement gaps in favour of boys in Australia, New Zealand, the United States, and the United Kingdom. However, on the other large-scale assessments in Australia and New Zealand, and the EQAO assessment in Ontario, there were no statistically significant gender differences in mathematics achievement. In all assessments in which data regarding the highest-performing group were analyzed, boys outperformed girls. Although the achievement gaps were not always in favour of boys and some assessments showed no gender differences, it is important to note that there were no statistically significant gender gaps in achievement in favour of girls in the assessments examined. Thus, there remains work to be done to ensure that boys and girls have equal opportunities to succeed on large-scale assessments of mathematics. 
Table 1: Summary of gendered mathematics achievement trends on large-scale assessments, by geographic location.

\begin{tabular}{|c|c|c|c|c|c|}
\hline $\begin{array}{c}\text { Geographic } \\
\text { location }\end{array}$ & Assessment(s) & Level(s) & Year(s) & $\begin{array}{c}\text { Overall } \\
\text { Achievement } \\
\text { Trends }\end{array}$ & $\begin{array}{c}\text { Trends at } \\
\text { Highest } \\
\text { Achievement } \\
\text { Level } \\
\end{array}$ \\
\hline U.S. & NAEP & $\begin{array}{l}\text { Grade } 4, \\
8 \text {, and } 12\end{array}$ & $1990-2003$ & $\begin{array}{c}\text { Boys }>\text { Girls } \\
\text { (small gap), } \\
\text { increased with } \\
\text { grade level }\end{array}$ & $\begin{array}{c}\text { Boys }>\text { Girls } \\
\text { (pronounced } \\
\text { gap) }\end{array}$ \\
\hline U.S & SAT & S.S. & $1982-1995$ & Boys $>$ Girls & Boys $>$ Girls \\
\hline $\begin{array}{l}\text { Aust. and } \\
\text { N.Z. }\end{array}$ & $\begin{array}{c}\text { Various } \\
\text { assessments }\end{array}$ & $\begin{array}{l}\text { E.S. and } \\
\text { S.S. }\end{array}$ & $2000-2004$ & $\begin{array}{c}\text { No significant } \\
\text { difference, but } \\
\text { Boys }>\text { Girls in } \\
\text { mean scores }\end{array}$ & Boys $>$ Girls \\
\hline $\begin{array}{l}\text { Aust., N.Z., } \\
\text { U.K., and } \\
\text { U.S. }\end{array}$ & PISA & $\begin{array}{l}\text { 15-year- } \\
\text { olds }\end{array}$ & 2006 & Boys $>$ Girls & N/A \\
\hline Ontario & EQAO & $\begin{array}{c}\text { Grade } 3, \\
6 \text {, and } 9\end{array}$ & $\begin{array}{c}2003 / 2004- \\
2007 / 2008\end{array}$ & $\begin{array}{c}\text { No significant } \\
\text { difference }\end{array}$ & N/A \\
\hline
\end{tabular}

Note: U.S. refers to the United States, Aust. refers to Australia, N.Z. refers to New Zealand, and U.K. refers to the United Kingdom. E.S. refers to elementary school, whereas S.S. refers to secondary school.

\section{Attitude}

This section focuses on student attitudes toward mathematics. As with the previous section, I begin by summarizing findings from researchers who analyzed data from large-scale assessments in culturally-similar countries to Canada. Then, I investigate Ontario students' attitudes toward mathematics, using data from student questionnaires associated with the EQAO large-scale provincial assessments in mathematics. I conclude by summarizing and drawing comparisons among the findings about students' attitudes toward mathematics from the culturally-similar countries and the province of Ontario. These comparisons will help to elucidate whether attitudes toward mathematics are similar among students in culturally-similar countries, even when the educational systems differ.

\section{International Perspectives}

The American NAEP large-scale assessment is accompanied by a questionnaire that asks students about mathematics course-taking, classroom experiences, and beliefs. McGraw et al. (2006) investigated NAEP questionnaire data from grade 4,8 , and 12 students from 1990 to 2003 . However, because there were changes in the questionnaires across years and grade levels, the authors only made comparisons within each year of the assessment and within each grade level. They found that females' attitudes toward mathematics and their mathematical self-concept were statistically significantly more negative than males', although males and females reported similar levels of understanding of the mathematics that was taught in class.

Data from Australia and New Zealand were examined by Vale (2008), who conducted a meta-analysis of national and international large-scale assessments of mathematics at the elementary and secondary school levels. From the 
questionnaires that accompanied many of the assessments, Vale noted very consistent findings at both the elementary and secondary school levels: Boys' attitudes toward and confidence in mathematics (measured by such constructs as enjoyment, self-confidence, self-perception, interest, and self-efficacy) were statistically significantly higher than those of girls. The only affective construct for which females had statistically significantly higher scores than males is mathematics anxiety. These findings not only held true across grade levels, but also endured over time.

\section{Ontario Perspective}

Along with the EQAO assessments in mathematics, students complete a questionnaire that includes questions regarding their attitudes toward mathematics, perceptions of their capabilities in mathematics, and mathematics practices, such as completing homework. The student questionnaires vary by age group, with older students answering more questions than younger students, including questions related to such topics as post-secondary plans.

Across all grade levels, there are significant gender differences in students' attitudes toward mathematics, and these gender differences have persisted for all five years for which data have been collected (2003/2004 to 2007/2008). Boys consistently have more favourable opinions of mathematics and their capabilities in the subject area (EQAO, 2008). Below, I summarize findings from recent (2007/2008) EQAO questionnaire data for questions that are identical across all grades: 'I like mathematics.' and 'I am good at mathematics.' Grades 3 and 6 students were provided with yes/no options for responses, whereas Grade 9 students were provided with Likert-scale options (e.g., "strongly agree," "agree"). Thus, in my reporting, those students who are deemed to "like mathematics" or feel they are "good at mathematics" are those who answered "yes" in Grade 3 and 6 or those who answered "strongly agree" or "agree" in Grade 9. These findings are summarized in the Table 2.

Table 2: Students' feelings toward mathematics, separated by grade and sex, 2007/2008 EQAO student questionnaire data.

\begin{tabular}{lcccccccc}
\hline Statement & \multicolumn{2}{c}{ Percentage of students agreeing with the statement } \\
\hline & \multicolumn{2}{c}{ Grade 3 } & \multicolumn{2}{c}{ Grade 6} & \multicolumn{2}{c}{$\begin{array}{c}\text { Grade } 9 \\
\text { Academic }\end{array}$} & \multicolumn{2}{c}{$\begin{array}{c}\text { Grade } 9 \\
\text { Applied }\end{array}$} \\
\hline & Boys & Girls & Boys & Girls & Boys & Girls & Boys & Girls \\
\hline $\begin{array}{l}\text { I am good at } \\
\text { mathematics. }\end{array}$ & $60 \%$ & $45 \%$ & $58 \%$ & $40 \%$ & $59 \%$ & $48 \%$ & $43 \%$ & $27 \%$ \\
$\begin{array}{l}\text { I like } \\
\text { mathematics. }\end{array}$ & $61 \%$ & $55 \%$ & $51 \%$ & $37 \%$ & $59 \%$ & $45 \%$ & $41 \%$ & $29 \%$ \\
\end{tabular}

As can be seen in Table 2, at every grade and academic level, statistically significantly more boys than girls agreed with the positive statements toward mathematics. A consistent percentage (approximately 60\%) of Grade 3, 6, and 9 Academic boys feel that they are good at mathematics; for girls at these levels, the percentage is also consistent, although lower than it is for boys (by a range of 11 to 15 percentage points). For both boys and girls in Grade 9 Applied mathematics, a course that typically includes students who are not as strong at 
mathematics, the percentage of students who feel they are good at mathematics is substantially lower than at any other level.

There is a decrease in the percentage of both boys and girls who like mathematics from Grade 3 to Grade 6, although there is a higher percentage of boys than girls at each level. At the Grade 9 Academic level, which typically includes students who are strong at mathematics, the percentage of boys and girls who like mathematics returns to high levels such as those at the Grade 3 level. However, similar to the previous statement about being good at mathematics, a far lower percentage of Grade 9 Applied students claimed to like mathematics. Only $41 \%$ of boys and $29 \%$ of girls in Grade 9 Applied agreed with this statement, which is the lowest percentage at any grade level, by $10 \%$ and $8 \%$ respectively.

\section{Summary: Attitude Data}

Questionnaire data from large-scale assessments of mathematics from the United States, Australia, and New Zealand show that boys tend to exhibit more confidence in their mathematics abilities and a more positive attitude toward mathematics than girls. This finding holds true both over time and across grade levels. Similarly, in Ontario, the EQAO questionnaire data indicate that females tend to show less confidence in their mathematics abilities and less favourable attitudes toward mathematics than males. These gender differences exist for students in Grade 3,6, and 9, with little variation being shown across five years of EQAO data collection. Generally, there is a smaller gender gap in terms of students liking mathematics (6 to 14 percentage points in favour of boys, across grade levels), as opposed to feeling confident in their mathematics abilities (14 to 18 percentage points in favour of boys, across grade levels). By far, the students who like mathematics the least and show the least confidence in their mathematics abilities are those in Grade 9 Applied, both boys and girls, which may be due to the fact that these tend to be the Grade 9 students who are weaker in the subject area.

\section{Participation}

This section focuses on student participation in non-mandatory secondary school mathematics courses and university mathematics degree programs. These educational levels were selected in order to investigate students' participation in mathematics once it is no longer mandatory, which may indicate their interest in and perceptions of the utility of mathematics. Students who participate in mathematics at these levels have the opportunity for mathematics-related fields of study in post-secondary education and, subsequently, mathematics-related careers, such as high school mathematics teachers and mathematicians. Thus, a lack of participation at the upper secondary school and university level will lead to a lack of professionals in mathematics-related fields, which then leads to a lack of role models in these fields. Examining gender differences in non-mandatory levels of study is particularly important in the field of mathematics, which has traditionally been male-dominated, particularly at higher levels of study and in mathematics-related careers. To investigate the current situation of participation in mathematics at non-mandatory levels of study, I begin with examples from 
Australia, England, and the United States at the secondary school and university level, and then examine similar statistics from Ontario. I conclude by comparing the findings from these culturally-similar counties and Ontario.

\section{International Perspectives}

Forgasz (2006) analyzed enrolment data of Australian students in Grade 12 mathematics courses from 2000 to 2004. She focused on calculus and algebra courses, which are typically required for continued study in mathematics at the university level in Australia. With the exception of the Australian Capital Territory, Forgasz found that there were more boys than girls enrolled in these Grade 12 mathematics courses in every other state and jurisdiction in the country. Furthermore, from 2000 to 2004, the overall enrolment in these courses declined, which was attributed to fewer girls enrolling in the courses.

Mendick (2005) examined enrolment data of 17- and 18-year-old secondary school students in A-level (Year 12 and 13) mathematics courses in England from 1994 to 2003, and found there was very little change in the proportion of males and females enrolled. Indeed, over this decade-long time period, the proportion of females enrolled only increased slightly, from $35 \%$ to $37 \%$. Although there is a trend toward an increasing percentage of females in A-level mathematics courses, it is a particularly slow trend, and females still constitute a clear minority of students participating in these courses. Completion of A-level mathematics courses is required for university-level study in mathematics, so not participating in these courses places students at a disadvantage.

In the United States, both historical and recent statistics for university mathematics degree programs highlight a decreasing trend in the proportion of women enrolled from the bachelor's degree level to the doctoral level (National Center for Education Statistics [NCES], 1997, 2008). For instance, in the $2005 / 2006$ academic year, $46.1 \%$ of bachelor's degrees, $41.3 \%$ of master's degrees, and $23.3 \%$ of doctoral degrees in mathematics were awarded to women (NCES, 2008). However, over time, the proportion of women in each of these degree programs has generally followed an increasing trend. For example, from the 1949/1950 academic year to the 1994/1995 academic year, the proportion of students earning bachelor's degrees in mathematics who were women increased from $22.6 \%$ to $46.8 \%$ (NCES, 1997). In sum, although more women in the United States are enrolling in mathematics degree programs over time, there are fewer women enrolled at each subsequent degree level, i.e., bachelor's, master's, and doctoral degrees.

\section{Ontario Perspective}

Since 1999, when the Ontario secondary school curriculum changed to a fouryear program (Grade 9 to Grade 12), students have been required to earn three mathematics credits in order to graduate with their Ontario Secondary School Diploma (Ontario Ministry of Education and Training, 1999). Of these three credits, at least one must be from a senior (Grade 11 or 12) mathematics course. Most students take their senior mathematics credit in Grade 11, and, consequently, there is very little difference at this grade level between males and females in the proportion of their courseload that is mathematics: $13.3 \%$ and 
$13.0 \%$ respectively in the 2004/2005 academic year (Curriculum System, 20042005a). I will thus focus my discussions on the Grade 12 level, when most students have already obtained their required mathematics credits and mathematics is thus optional. At this level, males have a higher proportion of mathematics courses in their timetables than females: $17.4 \%$ of males' classes are in mathematics, on average, as compared to $14.0 \%$ of females' classes (Curriculum System, 2004-2005a). In other words, in Grade 12, between onefifth and one-sixth of males' classes are in mathematics, whereas approximately one-seventh of females' classes are in mathematics, on average.

To provide more detail about Grade 12 mathematics participation, I now discuss participation in each of the courses at this level. There are six mathematics courses offered at the Grade 12 level in Ontario-one at the Workplace Preparation level, two at the College Preparation level, and three at the University Preparation level (Ontario Ministry of Education, 2007).

Table 3: Male/female enrolment percentages for Grade 12 Ontario mathematics courses, 2004-2005 Curriculum System data.

\begin{tabular}{lccc}
\hline Course title/code & $\begin{array}{l}\text { Suggested } \\
\text { destination }\end{array}$ & $\begin{array}{l}\text { Percentage } \\
\text { males }\end{array}$ & $\begin{array}{l}\text { Percentage } \\
\text { females }\end{array}$ \\
\hline $\begin{array}{l}\text { Advanced functions and introductory calculus } \\
\text { (MCB4U) }\end{array}$ & University & $52.9 \%$ & $47.1 \%$ \\
Geometry and discrete mathematics (MGA4U) & University & $66.0 \%$ & $34.0 \%$ \\
Mathematics of data management (MDM4U) & University & $49.0 \%$ & $51.0 \%$ \\
College and apprenticeship mathematics (MAP4C) & College & $62.2 \%$ & $37.8 \%$ \\
Mathematics for college technology (MCT4C) & College & $72.4 \%$ & $27.6 \%$ \\
Mathematics for everyday life (MEL4E) & Workplace & $59.2 \%$ & $40.8 \%$ \\
\hline
\end{tabular}

As shown in Table 3, in all but one of the Grade 12 mathematics courses, there is a greater proportion of males than females enrolling. The course with a higher percentage $(51 \%)$ of females than males, Mathematics of Data Management, is not required for entrance into university programs in Mathematics, Science, Engineering, or Computer Science at any Ontario university (Erdman, 2009). Conversely, the two University preparation mathematics courses with a higher percentage of males are required for entry into the aforementioned university programs (Erdman), so more males meet the requirements for these programs than do females. Notably, the trend of more males than females enrolling in Grade 12 mathematics courses in Ontario occurs across the academic levels, from Workplace to University preparation (Curriculum System, 2004-2005b). Therefore, in nearly all the Grade 12 mathematics courses offered in Ontario, there are more boys than girls.

At the university level in Ontario, far more males than females are enrolled in and graduate from degree programs in mathematical fields, and the proportion of women in these programs has been decreasing in the recent past. For instance, from 1992 to 2007, the proportion of graduates in Ontario from undergraduate degree programs in mathematical fields who were women decreased from $33.8 \%$ to $29.3 \%$ (Statistics Canada, 2010b). Similarly, at the master's degree level, the proportion of female graduates from these fields had a substantial decline, from $50.6 \%$ in 1992 to $43.5 \%$ in 2007 (Statistics Canada, 2010b). In contrast, the 
proportion of female graduates from doctoral programs in these fields increased from $16.7 \%$ in 1992 to $27.7 \%$ in 2007 (Statistics Canada, 2010b). However, the total number of students in these fields at this level is very small (a total of 72 doctoral graduates in 1992 and 141 doctoral graduates in 2007). Across the degree levels in mathematical fields, there is a higher percentage of women at the master's degree level than either the bachelor's or doctoral degree level, with the doctoral level having the smallest percentage of women.

Thus, at all levels of university study in Ontario, women constitute the minority of students in mathematical fields. These statistics stand in stark contrast to the statistic that approximately $60 \%$ of undergraduate students at Canadian universities are female, a trend that has remained stable for the past four years, and is consistent across the country (Statistics Canada, 2008). Therefore, to be proportionately represented, $60 \%$ of undergraduate students in mathematical fields should be women, which is approximately twice their current representation in these fields.

\section{Summary: Participation Data}

As demonstrated, participation rates of males and females in non-mandatory secondary school courses and university degree programs in mathematics in Australia, England, the United States, and Ontario showed marked gender differences. Findings from Australia and England regarding participation in upper-year secondary school mathematics were similar: Fewer girls than boys participate in these courses. At the university level in the United States, the proportion of women in mathematics degree programs has increased over time in each level of study (bachelor's, master's, and doctoral degrees). However, the proportion of women decreases from the bachelor's to doctoral degree level, and this trend has remained constant over time.

In Ontario, similar findings occurred with regard to non-mandatory secondary school mathematics courses: Boys in Grade 12 have a higher proportion of mathematics courses in their timetables, on average, than do girls. In five of the six Grade 12 mathematics courses offered in Ontario, boys constitute the majority of the course enrolment. At the university level, the proportion of women obtaining degrees in mathematical fields in Ontario has always been a minority, and has decreased over time at all but the doctoral level.

\section{Concluding Remarks}

The data presented on students' mathematics achievement, attitudes, and participation, from the elementary to university level, strongly challenge the perception that "gender issues" in mathematics have been "solved" in developed countries. An examination of data from such countries as the United States and Australia, and the Canadian province of Ontario, indicates many similarities across these geographic locales with regard to mathematics achievement, attitudes, and participation. Gender gaps in achievement at the elementary and secondary level were usually shown to be statistically insignificant, but when they existed, they favoured boys. Over time and across grade levels, boys generally showed more positive attitudes toward mathematics and greater confidence in their mathematics abilities than girls. At the senior secondary 
school level, the participation of boys in non-mandatory university-preparation mathematics classes was significantly higher than that of girls, and this trend continued at the university level, with women constituting the minority of students in degree programs in mathematical fields.

These trends indicate that there is still much work to be done in order to achieve gender equity in mathematics with regard to students' attitudes, achievement, and participation. As many studies (for example, Fennema \& Sherman, 1977; Meyer \& Koehler, 1990; van Langen, Rekers-Mombarg, \& Dekkers, 2006) have shown, these factors are highly inter-related: Students with positive attitudes toward mathematics have greater achievement, and both of these factors are related to participation in mathematics.

There are many challenges that females currently face outside the classroom with regard to mathematics, such as stereotypical views held by parents and societal views of mathematics as being incongruent with being feminine. These deeply entrenched societal views and stereotypes will be difficult to change and will take many years to slowly evolve; however, change can begin now from within the classroom. As a starting point, changes in instructional practices in mathematics need to occur in order to provide more meaningful experiences for females in mathematics. Feminist researchers (for example, Boaler, 1997; Burton, 1995; Whitten \& Burciaga, 2001) advocate for creating supportive, inquiry-focused mathematics classroom environments wherein females' voices are heard and many approaches to solving problems are valued. For instance, rather than the traditional focus in mathematics on memorization and rulefollowing, researchers (for example, Becker, 1995; Belenky, Clinchy, Goldberger, \& Tarule, 1986; Morrow \& Morrow, 1995) suggest that focusing more on conceptual understanding and connecting mathematics to students' lives may help both males and females to better relate to and understand the subject. These approaches have been shown to have positive outcomes with respect to all students' achievement, attitudes, and participation in mathematics, but particularly for girls and women. Thus, as a means of challenging the gender inequities demonstrated in this article, classroom-based changes may be a key starting point.

\section{References}

Becker, J. R. (1995). Women's ways of knowing in mathematics. In P. Rogers \& G. Kaiser (Eds.), Equity in mathematics education: Influences of feminism and culture (pp.163-174). London, England: Falmer.

Belenky, M. F., Clinchy, B. M., Goldberger, N. R., \& Tarule, J. M. (1986). Women's ways of knowing: The development of self, voice, and mind. New York, NY: Basic Books.

Boaler, J. (1997). Reclaiming school mathematics: The girls fight back. Gender and Education, 9(3), 285-305.

Burton, L. (1995). Moving towards a feminist epistemology of mathematics. In P. Rogers \& G. Kaiser (Eds.), Equity in mathematics education: Influences of feminism and culture (pp. 209226). London: Falmer.

Curriculum System. (2004-2005a). Grade 11 and 12 math enrolment as a percentage of all course enrolment, Province of Ontario.

Curriculum System. (2004-2005b). Percentage of overall course enrolment in grade 11 and grade 12 math courses by gender, Province of Ontario. 
Education Quality and Accountability Office (EQAO). (2008). Ontario student achievement, English-language schools: EQAO's provincial report on the results of the 2007-2008 assessment of reading, writing and mathematics - Primary division (Grades 1-3) and Junior division (Grades 4-6), and the Grade 9 assessment of mathematics. Toronto, Canada: Queen's Printer for Ontario.

Erdman, W. (2009). Grade $12 U$ math requirements for 2010 Ontario university admissions. Retrieved November 5, 2009, from http://www.oame.on.ca/main/files/EDUGr12/UnivMathReq2010.pdf.

Fennema, E., \& Sherman, J. (1977). Sex-related differences in mathematics achievement, spatial visualization, and affective factors. American Educational Research Journal, 14(1), 51-71.

Forgasz, H. J. (2006). Australian year 12 'intermediate' level mathematics enrolments 2000-2004: Trends and patterns. In P. Grootenboer, R. Zevenbergen, \& M. Chinnappan (Eds.), Identities, cultures and learning spaces (pp. 211-220). Adelaide, Australia: MERGA.

Fruchter, B. (1954). Measurement of spatial abilities: History and background. Educational and Psychological Measurement, 14(2), 387-395.

Gavin, M. K. (1996). The development of math talent: Influences on students at a women's college. Journal of Secondary Gifted Education, 7(4), 1-10.

Karp, K., \& Shakeshaft, C. (1997). Restructuring schools to be math friendly to females. National Association of Secondary School Principals (NASSP) Bulletin, 81(586), 84-93.

McGraw, R., Lubienski, S. T., \& Strutchens, M. E. (2006). A closer look at gender in NAEP mathematics achievement and affect data: Intersections with achievement, race/ethnicity, and socioeconomic status. Journal for Research in Mathematics Education, 37(2), 129-150.

Mendick, H. (2005). Mathematical stories: Why do more boys than girls choose to study mathematics at the AS-level in England? British Journal of Sociology of Education, 6(2), 235251.

Meyer, M. R., \& Koehler, M. S. (1990). International influences on gender differences in mathematics. In E. Fennema \& G. Leder (Eds.), Mathematics and gender: Influences on teachers and students (pp. 60-95). New York, NY: Teachers College Press.

Morrow, C., \& Morrow, J. (1995). Connecting women with mathematics. In P. Rogers \& G. Kaiser (Eds.), Equity in mathematics education: Influences of feminism and culture (pp. 13-26). London, England: Falmer Press.

National Center for Education Statistics. (1997). Table 291-Earned degrees in mathematics conferred by institutions of higher education, by level of degree and sex of student: 1949-50 to 1994-95. Retrieved April 1, 2009, from http://nces.ed.gov/programs/digest/d97/d97t291.asp

National Center for Education Statistics (NCES). (2008). Table 265-Bachelor's, master's, and doctor's degrees conferred by degree-granting institutions, by sex of student and field of study: 2005-06. Retrieved April 1, 2009, from http://nces.ed.gov/programs/digest/d07/tables/dt07 265.asp?referrer=list

National Council of Teachers of Mathematics. (1989). Curriculum and evaluation standards for school mathematics. Reston, VA: NCTM.

National Council of Teachers of Mathematics. (1991). Professional standards for teaching mathematics. Reston, VA: NCTM.

National Council of Teachers of Mathematics. (1995). Assessment standards for school mathematics. Reston, VA: NCTM.

National Council of Teachers of Mathematics. (2000). Principles and standards for school mathematics. Reston, VA: NCTM.

Ontario Ministry of Education. (2005a). The Ontario curriculum grades 1-8: Mathematics revised. Toronto, Canada: Queen's Printer for Ontario.

Ontario Ministry of Education. (2005b). The Ontario curriculum grades 9 and 10: Mathematics revised. Toronto, Canada: Queen's Printer for Ontario.

Ontario Ministry of Education. (2007). The Ontario curriculum grades 11 and 12: Mathematics revised. Toronto, Canada: Queen's Printer for Ontario.

Ontario Ministry of Education and Training. (1999). Ontario secondary schools, grades 9 to 12: Program and diploma requirements. Retrieved March 25, 2009 from http://www.edu.gov.on.ca/eng/document/curricul/secondary/oss/oss.pdf 
Organization for Economic Co-Operation and Development (OECD). (2007). Table 6.2c - Mean score, variation and gender differences in student performance on the mathematics scale. Retrieved June 16, 2007, from http://www.oecd.org/dataoecd/31/0/39704446.xls

Picker, S. H., \& Berry, J. S. (2000). Investigating pupils' images of mathematicians. Educational Studies in Mathematics, 43(1), 65-94.

Picker, S. H., \& Berry, J. S. (2001). Your students' images of mathematicians and mathematics. Mathematics Teaching in the Middle School, 7(4), 202-208.

Stafford, R. E. (1972). Heredity and environmental components of quantitative reasoning. Review of Educational Research, 42(2), 183-201.

Statistics Canada. (2008, February 7). University degrees, diplomas, and certificates awarded. The Daily. Retrieved March 25, 2009, from http://www.statcan.gc.ca/Daily/English/080207/d080207c.htm

Statistics Canada. (2010a). Table 051-001 - Estimates of population, by age group and sex for July 1, Canada, provinces and territories, annual (persons unless otherwise noted), CANSIM (database), Using E-STAT (distributor). Retrieved July 1, 2010, from http://estat.statcan.gc.ca/ Statistics Canada. (2010b). Table 477-0014 - University degrees, diplomas and certificates granted, by program level, Classification of Instructional Programs, Primary Grouping (CIP_PG) and sex, annual (number), CANSIM (database), Using E-STAT (distributor). Retrieved June 28, 2010, from http://estat.statcan.gc.ca/

Vale, C. (2008, July). Trends and factors concerning gender and mathematics in Australasia. Paper presented at the 11th International Congress on Mathematics Education (ICME-11). Monterrey, Mexico. Available at http://tsg.icme11.org/document/get/169.

van Langen, A., Rekers-Mombarg, L, \& Dekkers, H. (2006). Sex-related differences in the determinants and process of science and mathematics choice in pre-university education. International Journal of Science Education, 28(1), 71-94.

Whitten, B. L., \& Burciaga, J. R. (2001). First steps toward a more feminist, multicultural physics. In E. L. MacNabb, M. J. Cherry, S. L. Popham, \& R. P. Prys (Eds.), Transforming the disciplines: A women's studies primer (pp. 169-176). Binghamton, NY: Hawthorn.

Jennifer Hall (jennifer.e.hall@uottawa.ca) is a doctoral candidate and a part-time professor in mathematics education at the University of Ottawa. Her research interests include gender issues in mathematics and societal views of mathematics and mathematicians. 